\title{
Evaluation of HBsAg Quantification as Surrogate to HBV DNA Viral Load in Hepatitis B Infected Patients in Anambra State, Nigeria
}

\author{
Chinwe Obiomah1, Grace Amilo², Israel Ndulue ${ }^{1}$ \\ ${ }^{1}$ Department of HIV Care, Nnamdi Azikiwe University Teaching Hospital, Nnewi, Nigeria \\ ${ }^{2}$ Department of Medical Laboratory Science, Nnamdi Azikiwe University Nnewi Campus, Nnewi, Nigeria \\ Email: chinweobioma6@gmail.com
}

How to cite this paper: Obiomah, C., Amilo, G. and Ndulue, I. (2020) Evaluation of HBsAg Quantification as Surrogate to HBV DNA Viral Load in Hepatitis B Infected Patients in Anambra State, Nigeria. American Journal of Molecular Biology, 10, 129-140.

https://doi.org/10.4236/ajmb.2020.103009

Received: January 21, 2020

Accepted: May 28, 2020

Published: June 1, 2020

Copyright $\odot 2020$ by author(s) and Scientific Research Publishing Inc. This work is licensed under the Creative Commons Attribution International License (CC BY 4.0).

http://creativecommons.org/licenses/by/4.0/

(c) (i) Open Access

\begin{abstract}
Hepatitis B is an infectious disease of great public health importance. Nigeria is one of the countries with the highest incidence of Hepatitis B Virus (HBV) infection worldwide. However, the accessibility and affordability of HBV DNA quantification (viral load) assay is the key laboratory test for therapy initiation, and monitoring is a challenge to HBV management. This study aimed at determining the relationship between HBV DNA quantification and routine haemato-serological parameters in order to develop a more cost-effective diagnostic algorithm for Hepatitis B management. Cross sectional study design was used with a total of 264 subjects comprising of 88 HBsAg seropositive treatment naïve subjects, $88 \mathrm{HBsAg}$ seropositive subjects on antiviral therapy as case subjects and 88 age-matched apparently healthy HBsAg seronegative individuals were recruited as control subjects. Hepatitis B Virus DNA assay was performed using real time PCR technique while ELISA technique was used for Hepatitis B surface antigen quantification. HBsAg quantification showed strong positive correlation with HBV DNA viral load both in treatment and non-treatment groups $(r=0.673 ; p<0.001)$. However, the Receiver Operation Characteristics curve indicated a very poor performance characteristics (AUC $=0.537, \mathrm{p}=0.002$ ). The non-treatment group has higher viral load $(\mathrm{M}=805.50 \mathrm{IU} / \mathrm{ml})$ compared with treatment group $(\mathrm{M}=65.50 \mathrm{IU} / \mathrm{ml})(\mathrm{p}<0.001)$. There was a significant difference in HBV DNA levels among the four serological patterns observed in the study ( $\mathrm{p}$ $<0.001$ ). This study has revealed that HBsAg quantification has strong correlation with $\mathrm{HBV}$ viral load but might not be efficient in clinical practice as a predictor of serum HBV viral load due to its poor performance characteristics in identifying high positive viral load.
\end{abstract}




\section{Keywords}

Hepatis B Virus, HBsAg Quantification, HBV DNA

\section{Introduction}

Hepatis B is a top health priority worldwide and a devastating cause of morbidity and mortality [1]. Hepatitis B is an infectious disease of great public health importance caused by hepatitis B virus (HBV). It is an enveloped DNA virus that infects the liver and causes hepatocellular necrosis and inflammation [2]. This virus belongs to the family hepadnaviridae and genus orthohepadnavirus and it is the only hepadnavirus that causes infection in humans [3]. It is 100 times more infectious than the most dreaded human immunodeficiency virus infection and 10 times more infectious than hepatitis C virus [4]. Hepatitis B virus is one of several viruses known to cause viral hepatitis and continues to be the major cause of viral hepatitis in the developing and underdeveloped world. In addition to causing chronic liver disease and cirrhosis, it has a formidable track record of being linked to primary hepatocellular carcinoma. It is estimated that $\mathrm{HBV}$ and HCV are the root cause of about $80 \%$ of all hepatocellular carcinomas (HCC) by promoting cirrhosis which significantly reduced the life expectancy of the infected patients [5].

About 257 million people are chronically infected annually and about 2 in 3 people with Hepatitis B do not know they are infected [6]. Recent statistics indicate that not less than 23 million Nigerians are estimated to be infected with the $\mathrm{HBV}$, making Nigeria one of the countries with the highest incidence of HBV infection in the world [7]. A national study done in Nigeria in 2016 shows a prevalence rate of 12.4 percent [8]. This worldwide burden of hepatitis B mandates accurate and timely diagnosis of patients infected with HBV and the use of treatment strategies derived from evidence-based guidelines. Most hepatitis B patients are asymptomatic in the early stage as specific clinical symptoms often occur at advanced disease stages, which are usually irreversible. Hence, the prognosis of the infection to liver disease is very crucial. The presence of derangement in specific laboratory analytes at the early stage of infection may signal a risk of fibrosis, cirrhosis and ultimately HCC.

Among all the several clinical diagnostic tests which have been developed for the detection of HBV infections, the serum HBV DNA level is a key factor affecting the initiation of antiviral therapy and evaluation of its efficacy [9]. Evaluation of the relationship between the serum HBV DNA levels and hepatic pathology is a current hotspot in the diagnosis and treatment of CHB [10]. Quantification of the HBsAg levels has received renewed attention because of its diagnostic potential in predicting the response to antiviral treatment and identifying the infection status of an individual [11]. Determination of the circulating levels of HBsAg could provide crucial information that could complement the mea- 
surement of HBV DNA. Studies of HBV infections conducted under various clinical settings have suggested that serum HBsAg could be used as a combinative or substitutive marker of HBV DNA levels [12]. Hepatitis B is an expensive disease to manage and numerous challenges exist for its effective management, particularly in resource-limited regions where Nigeria falls. Accessibility, affordability and high turnaround time of HBV DNA Viral load test have been a challenge to most Hepatitis $B$ patients. This study sets to evaluate the relationship between HBV DNA quantification and HBsAg quantification.

\section{Materials and Methods}

\subsection{Study Area}

The study was carried out at the Gastroenterology Unit of Nnamdi Azikiwe University Teaching Hospital (NAUTH), a tertiary institution in South Eastern Nigeria which is a referral center for Hepatitis B care in Nigeria.

\subsection{Study Design}

Cross sectional study design was used in the study. A total of 264 subjects were recruited which comprised of $88 \mathrm{HBsAg}$ seropositive treatment naïve subjects, 88 HBsAg seropositive subjects on antiviral therapy (Tenofovir $300 \mathrm{mg}$ daily/Entecavir $0.5 \mathrm{mg}$ daily or Pegylated interferons $180 \mu \mathrm{g}$ weekly) as case subjects and 88 age-matched apparently healthy HBsAg seronegative individuals were recruited as control subjects.

\subsection{Sample Size Determination}

Using $\mathrm{G}^{*}$ Power software version 3.0.10, power analysis for a one-way ANOVA with three groups was conducted to determine a sufficient sample size using an alpha of 0.05 , a power of 0.96 , and a medium effect size $(f=0.25)$. Based on the aforementioned assumptions, the calculated sample size of 264, with 88 subjects per group has $96 \%$ power to detect a difference of 0.25 at significance level of $0.05[13]$.

\subsection{Sampling Technique}

Purposive sampling technique was employed in selecting the participants based on the inclusion criteria. Patients that gave their consent who also met the selection criteria were recruited as they come to the clinic until the sample size was completed.

\subsection{Sample Collection}

After obtaining informed consent, $10 \mathrm{ml}$ of venous blood was collected from the fore arm of each subjects using a disposable syringe; $7 \mathrm{ml}$ was dispensed to a sterile $\mathrm{K}_{2}$-EDTA vacutainer $(1.2 \mathrm{mg} / \mathrm{ml}$ concentration) for hepatitis B DNA Viral load, hepatitis B panel, complete blood count, retroviral screening (RVS) and anti HCV screening while $3 \mathrm{ml}$ was added to a sterile plain container for HBsAg 
quantitation, HBcAb IgM titre quantitation, HDV IgG assay, Gamma Glutamyl Transferase (GGT) and liver function tests. The plasma and serum samples were separated into sterile plastic containers and preserved at $-86^{\circ} \mathrm{C}$.

\subsection{Ethical Approval}

Ethical approval was sought and obtained from the Ethics Committee of Nnamdi Azikiwe University Teaching Hospital Nnewi before the commencement of this study (Reference: NAUTH/CS/66/VOL.10/187/2017/096).

\subsection{Inclusion Criteria}

Participants included in this study were hepatitis B seropositive subjects aged 18 to 65 years attending Gastroenterology Clinic of NAUTH, Nnewi and apparently healthy HBsAg seronegative individuals (NAUTH staff, students and others) who gave their consent.

\subsection{Exclusion Criteria}

Those patients who were co-infected with HIV, HDV and HCV including HBsAg seronegative subjects who have received HBV vaccination were excluded from the study with those less than 18 years and above 65 years.

\subsection{Laboratory Diagnosis}

HBV DNA Viral Load using Cobas Ampliprep/Taqman Real Time PCR Technique (Roche Molecular System Inc., USA as described by Iregbu and Nwajiobi-Princewill (2016) [2]

Principle: Molecular biology technique based on polymerase chain reaction (PCR) for simultaneously amplification and quantification of target HBV DNA. The test permits automated specimen preparation followed by automated PCR amplification and detection of HBV target DNA and HBV Quantitation Standard (QS) DNA. The HBV DNA in the plasma sample is extracted in the Cobas Ampliprep using Magnetic Glass Particle technology which is based on the affinity of DNA for silica gel-covered magnetic beads. The extracted HBV DNA is transferred to Taqman analyzer alongside Master Mix reagent which contains primer pairs and probes specific for both HBV DNA and HBV QS DNA. The detection of amplified DNA is performed using a target-specific and a QS-specific dual-labeled oligonucleotide probes that permit independent identification of HBV amplicon and HBV QS amplicon. The quantitation of HBV viral DNA is performed using the HBV QS added to each specimen at a known copy number and is a non-infectious DNA construct that contains HBV sequences with identical primer binding sites as the HBV target DNA and a unique probe binding region that allows HBV QS amplicon to be distinguished from HBV amplicon. The COBAS TaqMan Analyzer calculates the HBV DNA concentration in the test specimens by comparing the HBV signal to the HBV QS signal for each specimen and control. 


\section{Procedure}

The frozen plasma was placed at room temperature until completely thawed before use. The High Positive, Low Positive and Negative controls were removed from $2^{\circ} \mathrm{C}-8^{\circ} \mathrm{C}$ storage and brought to room temperature before use. All reagent cassettes were removed from $2^{\circ} \mathrm{C}-8^{\circ} \mathrm{C}$ storage and loaded immediately onto the COBAS AmpliPrep Instrument and allowed to equilibrate to ambient temperature on the instrument for at least 30 minutes before the first specimen was processed. The appropriate number of reagent cassette racks, sample racks with Input S-tubes, SPU racks, K-tip racks, K-tube racks and K-carriers on K-carrier racks were loaded onto the respective rack positions of the COBAS AmpliPrep Instrument. Sample rack was prepared by attaching a barcode label clip to each sample rack position where a specimen (S-tube) was to be placed. The specific barcode label clips for the controls were attached to each sample rack position where the controls (S-tube) were to be placed. One Input S-tube was placed into each position containing a barcode label clip.

The Amplilink software was used to create specimen orders for each specimen and control in the Orders window Sample folder and HBV test definition file was selected and saved. The specimen and controls were vortexed for 5 seconds and $650 \mu \mathrm{L}$ added to the S-tubes. The tubes were then inserted in the sample rack and loaded to the Ampliprep. The Amplilink software was used to start the COBAS Ampliprep. At the completion of the COBAS TaqMan Analyzer run, the Results Report was validated and printed [14].

HBsAg Quantification by ELISA Technique (Fortress Diagnostics Limited United Kingdom as described by Bhatnagar et al., 1982) [15]

Principle: Antibody sandwich ELISA method in which polystyrene microwell strips pre-coated with monoclonal antibodies reacts with specific $\mathrm{HBsAg}$ in the Patient's serum to form specific immunocomplex and is captured on the solid phase during incubation. During the second incubation, the second antibody conjugated with horseradish peroxidase (HRP) enzyme binds to any anti-HBs-HBsAg complexes previously formed during the first incubation and the unbound HRP-conjugate is then removed by washing. The complex then reacts with the enzyme substrate to generate a coloured solution whose intensity is proportional to the amount of the specific antigen present in the sample.

\section{Procedure}

The wells were marked and $20 \mu \mathrm{l}$ of Specimen Diluent were added into each well except the blank. Then $100 \mu \mathrm{l}$ of Positive control, Negative control and Specimen were added into their respective wells except the blank. The plate was covered with plate cover and incubated for 60 mins at $37^{\circ} \mathrm{C}$. At the end of the incubation, the plate cover was removed and discarded, $50 \mu \mathrm{HRP}$-Conjugate were added into each well except the blank and mixed by tapping the plate gently. The plate was then covered and incubated at $37^{\circ} \mathrm{C}$. At the end of the second incubation, each well was washed times with diluted buffer allowing microwells to soak for 30 - 60 secs each time. After the final washing cycle, the plate was 
turned down onto blotting paper and tapped to remove any remnant. After the washing, $50 \mu \mathrm{l}$ of Chromogen A and $50 \mu \mathrm{l}$ of Chromogen B solutions were added into each well including the blank incubated in the dark at $37^{\circ} \mathrm{C}$ for 30 mins. After the incubation, $50 \mu \mathrm{l}$ of stop solution was added into each well using multichannel pipette and mixed gently. The blank was then used to calibrate the plate reader and the absorbance was read at $450 \mathrm{~nm}$.

\section{Statistical Analysis}

Data obtained were analyzed using Statistical Package for Social Sciences (SPSS) version 20) software. Data were expressed as mean \pm SD and median. The significance of differences in mean values among groups was analyzed using one-way ANOVA for normally distributed variables, while Kruskall Wallis was used to analyze the significant differences in median values among different groups for variables not normally distributed. Mann-Whitney was also used to analyze significant differences between groups. Spearman's correlation coefficient was used to assess the levels of relationship between two variables. Regression analysis and receiver Operators curve were also used appropriately. The level of significance was considered at $\mathrm{p}<0.05$.

\section{Results}

Median serum levels of HBV-DNA concentration and HBsAg Titers of the hepatitis $B$ subjects

Table 1 shows that the median serum HBV DNA level observed in the whole cohort ( $n=176)$ was $422.50 \mathrm{IU} / \mathrm{mL}$, whereas the median serum HBsAg titer was $1350.50 \mathrm{IU} / \mathrm{mL}$. There was no significant difference in the median HBV DNA level in the male group compared with the female group patients; $475 \mathrm{IU} / \mathrm{mL}$ ) versus $337 \mathrm{IU} / \mathrm{mL}$ ); $\mathrm{p}=0.523$. A similar pattern was observed for the HBsAg titer whose median values did not show significant gender differences.

Correlation between serum HBsAg titers and HBV-DNA in: 1) the whole hepatitis B patient cohort, 2) drug treatment group, 3) the treatment naïve group

Pearson's linear regression analysis indicated a significant positive correlation between HBsAg and HBV DNA among all patients at $r=0.627, \mathrm{p}<0.001$ as shown in Figure 1(a). Similarly, there were significantly positive correlations between HBsAg and HBV DNA for both the treatment and non-treatment groups, (Figure 1(b), $r=0.565, \mathrm{p}<0.001$ and Figure 1(c), $r=0.673, \mathrm{p}<0.001$ ).

Status of Hepatitis B subjects based on HBV DNA and HBsAg cut-off values

The $2 \times 2$ contingency table shows that HBsAg titration indicated a greater number $(n=54 ; 30.7 \%)$ of patients with abnormally high positive viral load. The same trend was observed in the drug treatment group (n (\%), 76 (43.2\%) vs. 21 $(11.9 \%))$ and the non-treatment group (n (\%), 91 (51.7\%) vs. $33(18.8 \%))$ respectively (Table 2). 


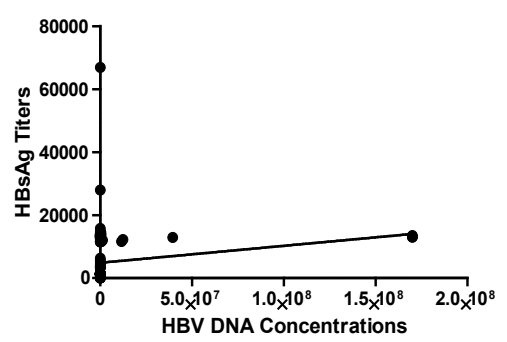

(a)

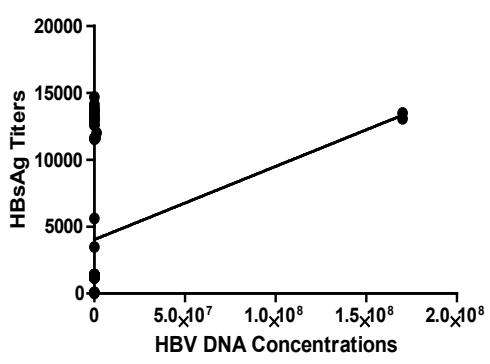

(b)

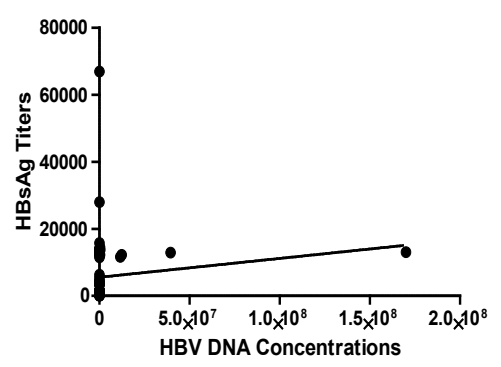

(c)

Figure 1. Correlation between serum HBsAg titers and HBV-DNA levels in: (a) the whole hepatitis B patient cohort $(\mathrm{n}=176)$; (b) drug treatment group $(\mathrm{n}=88)$; (c) the treatment naïve group $(\mathrm{n}=88)$.

Table 1. Median serum levels of HBV-DNA concentration and HBsAg Titers of the hepatitis B subjects.

\begin{tabular}{ccccc}
\hline Variable & Whole Cohort $(\mathrm{n}=176)$ & Males $(\mathrm{n}=100)$ & Females $(\mathrm{n}=76)$ & P Value \\
\hline HBV DNA $(\mathrm{IU} / \mathrm{mL})$ & 422.50 & 475.0 & 337.0 & 0.523 \\
HbsAg $(\mathrm{IU} / \mathrm{mL})$ & 1350.50 & 1355.0 & 1343.50 & 0.239 \\
\hline
\end{tabular}

Key: HBV DNA = Hepatitis B Viral DNA Quantification, HBsAg = Hepatitis B surface antigen quantification.

Table 2. Status of Hepatitis B subjects based on HBV DNA and HBsAg cut-off values.

\begin{tabular}{ccccc}
\hline \multirow{2}{*}{$\begin{array}{c}\text { Drug } \\
\text { Treatment }\end{array}$} & \multicolumn{2}{c}{ HBV-DNA Test } & \multicolumn{2}{c}{ HBsAg Titration } \\
\cline { 2 - 5 } & $\begin{array}{c}\text { High positive } \\
\text { (abnormal) n (\%) }\end{array}$ & $\begin{array}{c}\text { Low positive } \\
\text { (normal) n }(\%)\end{array}$ & $\begin{array}{c}\text { High positive } \\
(\text { abnormal) n }(\%)\end{array}$ & $\begin{array}{c}\text { Low positive } \\
(\text { normal) n (\%) }\end{array}$ \\
\hline Yes & $21(11.9)$ & $59(33.5)$ & $76(43.2)$ & $4(2.3)$ \\
No & $33(18.8)$ & $63(35.8)$ & $91(51.7)$ & $5(2.8)$ \\
Total & $54(30.7)$ & $122(69.3)$ & $167(94.9)$ & $9(5.1)$ \\
\hline
\end{tabular}

Viral load cut-off; HBV-DNA Test, abnormal $=\geq 2000$; normal $=<2000$; HBsAg Titration, abnormal $=$ $\geq 1000$; normal $=<1000$.

The ROC curve evaluating the quality or performance of HBsAg quantitation compared with the serum HBV-DNA test for the detection of hepatitis B patients' status.

The area under the curve, 0.537; $\mathrm{p}=0.002$ (Figure 2) showed that HBsAg quantitation indicated a very poor performance in discriminating or distinguishing between low positive and high positive viral loads in hepatitis B subjects, when compared with the serum HBV-DNA test. 


\section{Mean Age and Sex Distribution of Test Subjects}

Figure 3 shows the total number of female test subjects was 76 (42.7\%) while their male counterparts were $100(57.3 \%)$. The female subjects with ages less than 20 had the lowest frequency of 3 (3.9\%), this was followed by those female subjects greater than 50 years of age. Those females within the age bracket of 21 - 30 had the highest frequency of 32 (42.9). Those females within the ages of 31 40 were second to the highest with the frequency of 20 (26.9\%) while those within ages 41 - 50 were 13 (16.9\%). The male subjects with ages less than 20 also had the lowest frequency of 4 (3.9\%), this was followed by those male subjects greater than 50 years of age with frequency of $12(11.8 \%)$. Those male subjects within the age bracket of 31 - 40 had the highest frequency of 42 (43.1\%). Those within the ages of $21-30$ were second to the highest with the frequency of 26 (25.5\%) while those within ages 41 - 50 were $16(15.7 \%)$.

B

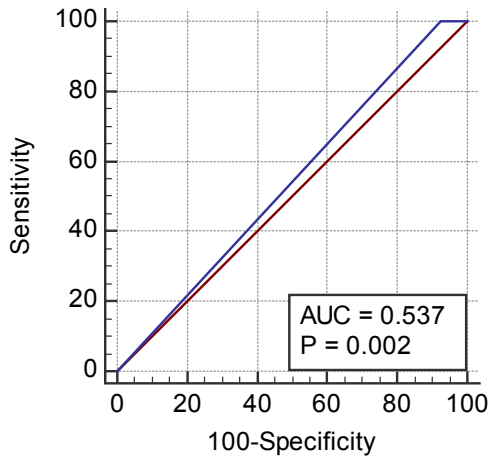

Figure 2. Receiver Operation Characteristics curve and area under curve indicating the diagnostic performance of HBsAg quantitation compared with the serum HBV-DNA test for the detection of high positive (abnormal) hepatitis B viral load.

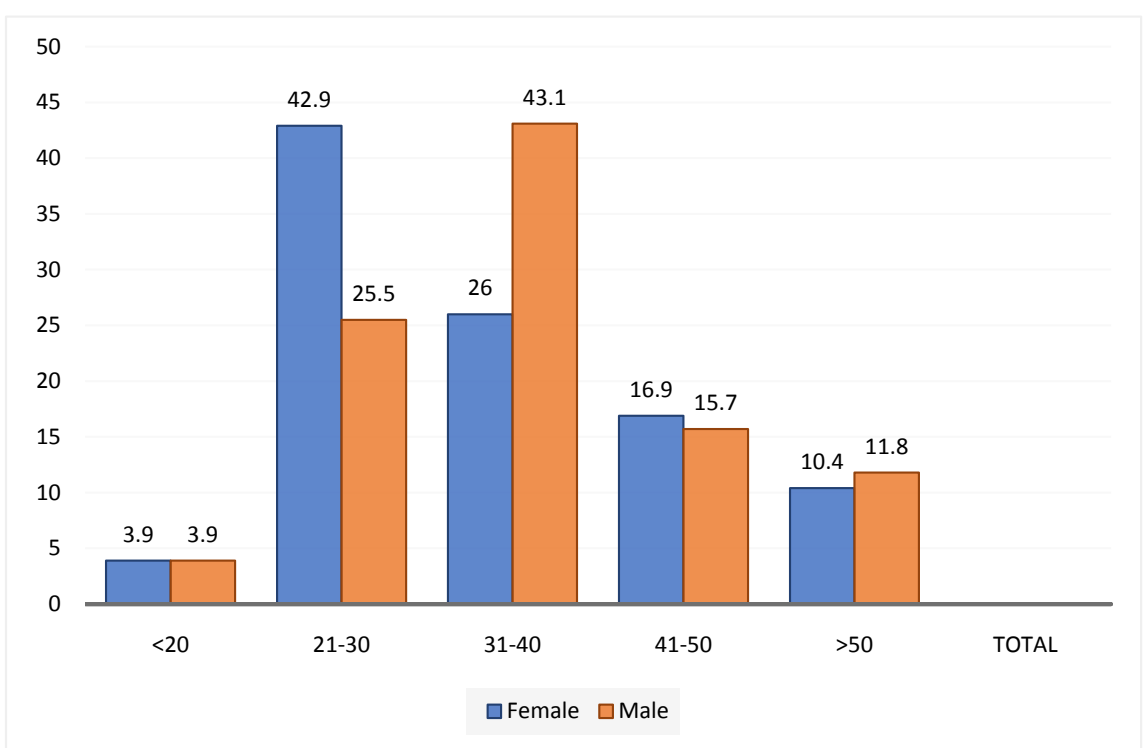

Figure 3. Mean age and sex distribution of test subjects $(\mathrm{N}=176)$. 


\section{Discussion}

This study hypothesized that quantification of HBsAg could be used to predict HBV viral load and thus be used to manage and monitor HBV patients. Quantification of HBsAg indirectly reflects the number of infected hepatocytes and is known to change over the natural course of chronic HBV infection (Seth et al., 2012) [16]. Also, during antiviral therapy, it could be used to differentiate true inactive carriers from patients in remission who are likely to progress to cirrhosis (Martinot-Peignoux et al., 2013) [17]. The HBsAg quantification in this study, showed a strong positive correlation with HBV viral load both in treatment and non treatment groups. This finding is in consonance with earlier reports of Alghamdi et al. (2013) [18] in Saudi Arabian population. Similar results were also recorded by Togo et al. (2011) [19] ( $\mathrm{r}=0.586, \mathrm{p}<0.001)$. Kim et al., 2011 [20] also reported a high significant correlation $(\mathrm{r}=0.657, \mathrm{p}<0.001)$. On the contrary, Ganji et al. (2011) [21] reported negative correlation between HBsAg and HBV viral load among chronic HBV infected individuals. The variations could be due to differences in disease stage, HBeAg status and HBV genotypes involved.

The above finding also agrees with Kim et al. (2010) [22] and supports the fact that hepatitis B surface antigen ( $\mathrm{HBsAg}$ ) is an important diagnostic marker, generally detectable in patients with acute and chronic infection; positive testing indicates high HBV replication in the liver, elevated blood HBV titers and greater infectivity to others. Level of HBsAg correlates with covalently closed circular DNA (cccDNA) level in the liver and reflects the amount of cccDNA inside hepatocytes. Furthermore, it correlates with the transcriptional activity of cccDNA and is considered a surrogate marker of infected cells. Although this study demonstrates a relationship between serum HBsAg titers and HBV DNA levels in the whole cohort of HBsAg positive patients and in its clinical subgroups, the area under the curve $(0.537 ; \mathrm{p}=0.002)$ showed that HBsAg quantitation indicated a very poor performance in discriminating or distinguishing between normal and abnormal viral loads in hepatitis B subjects, when compared with the serum HBV-DNA test. This suggests that HBsAg quantitation may not be an effective alternative to serum HBV-DNA quantification in hepatitis B virus infected patients. This finding is similar to the report of Mathia et al. (2017) [23]. HBV DNA is the template for gene transcription and replication and level is the most important and most direct etiological evidence for HBV.

The sex distribution of the subjects in this study showed that there were more males $100(57.2 \%)$ males and $76(42.8 \%)$ females. This shows that HBV infection is more prevalent in males than females and the finding is in keeping with the findings of Yewande et al. (2018) [24] which reported that males are 2.8 times more likely to get infected with HBV compared to their female counterparts. This could be due to the fact that males are more prone to risk factors and behaviours sexual intercourse, injection drug use, barbing et ce tera which predispose them to HBV infection. Regarding the age distribution, highest frequency of 
HBsAg seropositivity was found among the younger age group 21 - 30 followed by 31 - 40 group for both males and females. This agrees with the findings of Kolou et al. (2017) [25] carried out among age range 20 - 30 years old in Lome, Togo. Also another work done by Gheorghe et al. (2013) [26] gave a similar report. Considering the modes of transmission of HBV, the high sexual activity of individuals within these age brackets might explain this high frequency. The age group $<20$ had the least frequency both among males and females (3.9 both). The $>50$ age group were the second to the least of the subjects ( $9 \%$ females and $12 \%$ for females). This finding is in agreement with that of Yewande et al., (2018) [24]. The children $(<20)$ and the aged $(>50)$ are less prone to risky behaviours than the middle aged $(21-30,31-40)$.

\section{Conclusion}

This study has revealed that HBsAg quantification has strong correlation with HBV viral load but might not be efficient in clinical practice as a predictor of serum HBV viral load due to its poor performance characteristics in identifying high positive viral load.

\section{Conflicts of Interest}

The authors declare no conflicts of interest regarding the publication of this paper.

\section{References}

[1] WHO (2015) Guidelines for the Prevention, Care and Treatment of Persons with Chronic Hepatitis B Infection.

[2] Iregbu, K. and Nwajiobi-Princewill, P. (2016) Viral Load Pattern among Hepatitis B Surface Antigen-Positive Patients: Laboratory Perspective and Implications for Therapy. Annals of Medical and Health Science Research, 6, 95-99. https://doi.org/10.4103/2141-9248.181835

[3] Fairley, C. and Read, T. (2012) Vaccination against Sexually Transmitted Infections. Current Opinion in Infectious Diseases, 25, 66-72. https://doi.org/10.1097/QCO.0b013e32834e9aeb

[4] CDC (2003) Guidelines for Laboratory Testing and Result Reporting of Antibody to Hepatitis C Virus. Morbidity and Mortality Weekly Reports, 52, 1-16.

[5] Crossan, C., Tsochatzis, E.A., Longworth, L., Gurusamy, K., Davidson, B., Rodríguez-Perálvarez, M., Mantzoukis, K., O’Brien, J., Thalassinos, E., Papastergiou, V. and Burroughs, A. (2015) Cost-Effectiveness of Non-Invasive Methods for Assessment and Monitoring of Liver Fibrosis and Cirrhosis in Patients with Chronic Liver Disease: Systematic Review and Economic Evaluation. Health Technology As sessment, 19, 1-410. https://doi.org/10.3310/hta19090

[6] CDC (2018) What Is Viral Hepatitis? https://www.cdc.gov/hepatitis/abc/index.htm

[7] WHO (2017) Epidemiological Update: Increasing Mortality Calls for Action. Hepatitis B Global Report 17, 1-11.

[8] Olayinka, A.T., Oyemakinde, A., Balogun, M.S., Ajudua, A., Nguku, P., Aderinola, 
M., Egwuenu-Oladejo, A., Ajisegiri, S.W., Sha'aibu, S., Musa, B.O., Gidado, S. and Nasidi, A. (2016) Seroprevalence of Hepatitis B Infection in Nigeria: A National Survey. American Journal of Tropical Medicine Hygiene, 95, 902-907. https://doi.org/10.4269/ajtmh.15-0874

[9] Demiroren, K., Kocamaz, H. and Dogan, Y. (2015) The Importance of the Serum Quantitative Levels of Hepatitis B Surface Antigen and Hepatitis B e Antigen in Children with Chronic Hepatitis B. The Turkish Journal of Gastroenterology, 26, 36-41. https://doi.org/10.5152/tjg.2015.4636

[10] Cornberg, M., Wong, V.W., Locarnini, S., Brunetto, M., Janssen, H.L.A. and Chan, H.L. (2017) The Role of Quantitative Hepatitis B Surface Antigen Revisited. Journal of Hepatology, 66, 398-411. https://doi.org/10.1016/j.jhep.2016.08.009

[11] Li, J., Sun, X., Fang, J., Wang, C., Han, G. and Ren, W. (2017) Analysis of Intrahepatic Total HBV DNA, cccDNA and Serum HBsAg Level in Chronic Hepatitis B Patients with Undetectable Serum HBV DNA during Oral Antiviral Therapy. Clinics and Research in Hepatology and Gastroenterology, 41, 635-643. https://doi.org/10.1016/j.clinre.2017.03.004

[12] Chan, H.L., Thompson, A., Martinot-Peignoux, M., Piratvisuth, T., Cornberg, M., Brunetto, M.R., Tillmann, H.L., Kao, J.H., Jia, J.D., Wedemeyer, H., Locarnini, S. and Janssen, H.L. (2011) Hepatitis B Surface Antigen Quantification: Why and How to Use It? A Core Group Report. Journal of Hepatology, 55, 1121-1131. https://doi.org/10.1016/j.jhep.2011.06.006

[13] Faul, F., Erdfelder, E., Buchner, A. and Lang, A. (2013) G*Power Version 3.1.7 [Computer Software]. Uiversitat Kiel, Kiel. http://www.psycho.uni-duesseldorf.de/abteilungen/aap/gpower3/download-and-reg $\underline{\text { ister }}$

[14] Saldanha, J., Gerlich, W., Lelie, N., Dawson, P., Heermann, K. and Heath, A. (2001) An International Collaborative Study to Establish a World Health Organization International Standard for Hepatitis B Virus DNA Nucleic Acid Amplification Techniques. Vox Sanguinis, 80, 63-67. https://doi.org/10.1046/j.1423-0410.2001.00003.x

[15] Bhatnagar, P., Papas, H., Blum, D., Milich, D. and Nitecki, M. (1982) Immune Response to Synthetic Peptide Analogues of Hepatitis B Surface Antigen Specific for the Determinant. Proceedings of National Academy of Science, 79, 4400-4404. https://doi.org/10.1073/pnas.79.14.4400

[16] Seth, A. (2012) HBV Quantification in Clinical Practice. Journal of Clinical and EXperimental Hepatology, 2, 75-80. https://doi.org/10.1016/S0973-6883(12)60084-X

[17] Martinot-Peignoux, M., Lapalus, M., Asselah, T. and Marcellin, P. (2014) HBsAg Quantification: Useful for Monitoring Natural History and Treatment Outcome. Liver International, 34, 97-107. https://doi.org/10.1111/liv.12403

[18] Alghamdi, A., Aret, N., Hazmi, E., Hamoudi, W., Alswat, K., Helmi, A., Sanai, F. and Abdo, A. (2013) Correlation between Hepatitis B Surface Antigen Titers and HBV DNA Levels. The Saudian Journal of Gastroenterology, 19, 252-257. https://doi.org/10.4103/1319-3767.121035

[19] Togo, S., Arai, M., Tawada, A., Chiba, T., Kanda, T. and Fujiwara, K. (2011) Clinical Importance of Serum Hepatitis B Surface Antigen Levels in Chronic Hepatitis B. Journal of Hepatology, 18, 508-515. https://doi.org/10.1111/j.1365-2893.2011.01486.x

[20] Kim, Y., Cho, H., Choi, M., Lee, J., Koh, H. and Yoo, B. (2011) The Change of Quantitative HBsAg Level during the Natural Course of Chronic Hepatitis B. Liver International, 31, 817-823. https://doi.org/10.1111/j.1478-3231.2011.02516.x 
[21] Ganji, A., Esmaeilzadeh, A., Ghafarzadegan, K., Helalat, H., Rafatpanah, H. and Mokhtarifar, A. (2011) Correlation between HBsAg Quantitative Assay Results and HBV DNA Levels in Chronic HBV. Hepatitis Monthly, 11, 342-345.

[22] Kim, B.K., Kim, D.Y., Park, J.Y., Ahn, S.H., Chon, C.Y., Kim, J.K., Paik, Y.H., Lee, K.S., Park, Y.N. and Han, K.H. (2010) Validation of FIB-4 and Comparison with Other Simple Noninvasive Indices for Predicting Liver Fibrosis and Cirrhosis in Hepatitis B Virus-Infected Patients. Liver International, 30, 546-553. https://doi.org/10.1111/j.1478-3231.2009.02192.x

[23] Mathia, F., Ngayo, M., Karanja, S., Kalebi, A. and Lihana, R. (2017) Correlation of Quantitative Assay of HBsAg and Hepatitis B Virus DNA Levels among Chronic HBV Patients Attending Pathologist Lancet Laboratory in Nairobi, Kenya. Archives of Clinical Infectious Diseases, 12, 13306. https://doi.org/10.5812/archcid.13306

[24] Yewande, N., Adedayo, O., Babatunde, O., Solomon, B., Adebowale, O. and Babatunde, M. (2018) Hepatitis B Virus Infection among Sexually Active Individuals in Nigeria: A Cross-Secondary Study. Pan African Medical Journal, 30, 155. https://doi.org/10.11604/pamj.2018.30.155.14886

[25] Kolou, M., Katawa, G., Salou, M., Gozo-Akpako, K., Dossim, S., Kwarteng, A. and Prince-David, M. (2017) High Prevalence of Hepatitis B Virus Infection in the Age Range of 20-39 Years Old Individuals in Lome. Open Virology Journal, 11, 1-7. https://doi.org/10.2174/1874357901710011001

[26] Gheorghe, L., Csiki, I., Iacob, S. and Gheorge, C. (2013) The Prevalence and Risk Factors of Hepatitis B Virus Infection in an Adult Population in Romania: A Nationwide Survey. European Journal of Gastroenterology and Hepatology, 25, 56-64. https://doi.org/10.1097/MEG.0b013e328358b0bb 